\title{
PD-1/PD-L1 pathway in non-small-cell lung cancer and its relation with EGFR mutation
}

\author{
Mei $\mathrm{Ji}^{1 \dagger}$, Yan Liü ${ }^{2 \dagger}$, Qing Li ${ }^{3}$, Xiao-Dong Li', Wei-Qing Zhao ${ }^{1}$, Hanze Zhang ${ }^{4}$, Xiaofei Zhang ${ }^{5}$, Jing-Ting Jiang ${ }^{6}$ \\ and Chang-Ping $\mathrm{Wu}^{1 *}$
}

\begin{abstract}
Immunotherapy has become a crucial modality for non-small-cell lung cancer treatment. Recently, two immune checkpoints, PD-1 and PD-L1, have emerged as important targets for immunotherapy. Their antitumor efficacy has been confirmed by in vitro and in vivo studies. But the correlation between PD-1/PD-L1 expression and EGFR expression was controversial and needs more evidences to support the combination of PD-1/PD-L1 inhibitors and tyrosine kinase inhibitors.
\end{abstract}

Keywords: PD-1, PD-L1, Non-small-cell lung cancer, EGFR, Gene mutation

\section{Introduction}

Lung cancer, the leading cause of cancer-related deaths, has the highest incidence and mortality rates amongst all malignancies worldwide [1]. Lung cancer has an incidence of over 1.6 million cases/year accounting for $13 \%$ of all new cancer diagnoses and 1.4 million deaths/year accounting for $18 \%$ of all cancer-related deaths [2,3]. Particularly in China, both of the incidence and mortality rates of lung cancer are the highest over the world [4].

Amongst the various types of lung caners, non-smallcell lung cancer (NSCLC) comprises $80 \%-85 \%$ of all cases and more than $70 \%$ are diagnosed as unresectable advanced disease $[1,5]$. Though much progress has been obtained in optimizing the treatment of NSCLC, the prognosis for NSCLC patients remains poor, with the 5year overall survival (OS) rate of $15 \%$ of all stages [1].

Up to date, the pivot for curing advanced NSCLC has been the direct inhibition of tumor cell growth by cytotoxic agents or targeted small-molecule inhibitors. However, platinum-based chemotherapy only has a response rate of $20 \%-35 \%$ and a median OS of $10-12$ months, while targeted therapy with tyrosine kinase inhibitors (TKIs) can not prolong OS significantly [6] and moreover

* Correspondence: wcpjscz@163.com

${ }^{\dagger}$ Equal contributors

'Department of Oncology, The Third Affiliated Hospital of Soochow

University, Changzhou, China

Full list of author information is available at the end of the article eventual relapse or progression is inevitable. Hence, novel treatment strategies are urgently needed.

Given that cancers are recognized by human immune system, and under certain circumstances the immune system can obliterate tumors [7], many clinical physicians have considered immunotherapy as a treatment modality for NSCLC over the last several decades. It has already been found that chronic inflammation increases neutrophils, decreases lymphocytes, and increases cytokine release and interleukin secretion to reduce cancer cell apoptosis in lung [8]. Until recently, one promising breakthrough that NSCLC responds to immune checkpoint blockade has emerged, suggesting that NSCLC is an immunologically targetable disease.

$\mathrm{T}$ cells play pivotal effector-like roles in the complicated network of human the immune system. T cells hamper tumor development $[9,10]$ but unfortunately tumors can also prevent themselves from sustained $\mathrm{T}$ cell responses via so called immune checkpoints like CTLA-4, PD-1 and PD-L1 etc. [11]. Studies in mouse models have revealed that manipulation of inhibitory immune checkpoints could reduce $\mathrm{T}$ cell responses against tumors [12]. In additon, we know that NSCLC induces pro-tumorigenic immunosuppressive changes to evade the immune system, and these changes can be elicited by the inhibitors [13]. So immune checkpoint inhibitors can restore $\mathrm{T}$ cell resoponses and thus impede the tumor evasion of NSCLC. 
Mechanisms of PD-1 and PD-L1 as cancer immunotherapy PD-1, a type 1 transmembrane protein of the Ig superfamily [14], consists of an extracellular N-terminal IgV-like domain, a transmembrane domain, and a cytoplasmic tail [15] engaging in inhibitory signal transmission [16]. Being expressed on activated immune cell types including $\mathrm{T}$ cells, B cells, natural killer (NK) cells, NKT cells, dendritic cells (DCs), macrophages, and host tissues $[17,18]$, the expression on effector $\mathrm{T}$ cells is associated with constitutive antigen exposure and thus PD-1 has become a marker of T cell unresponsiveness or exhaustion [19].

PD-1 has two known ligands, PD-L1 (B7-H1) and PDL2 (B7-DC), which belong to B7 family [20,21]. PD-L1 is the major ligand and expressed on hematopoietic cells including T cells, B cells, DCs, macrophages and mast cells [22] as well as many nonhematopoietic cells including endothelial cells and numerous epithelial cells [23]. PD-L1 is expressed on many tumors including cancers developing in various organs such as head and neck, lung, stomach, colon, pancreas, breast, kidney, bladder, ovary, cervix, as well as melanoma, glioblastoma, multiple myeloma, lymphoma, and various leukemias [24-28], thereby inhibits effective anti-tumor immune responses mediated by PD1-expressed T cells [11].

PD-1 and PD-1 L interact with each other and then inhibit expression of multiple transcription factors of $\mathrm{T}$ cells such as GATA-3 and T-bet [29]. Besides, the PD-1/ PD-L1 interaction inhibits the proliferation, survival, and effector function of $\mathrm{CD}^{+}$cytotoxic T lymphocyte (CTL) and thus induces apoptosis of tumor-infiltrating $\mathrm{T}$ cells [30]. Ectopic PD-L1 expression in tumor cells in a syngeneic transplant model facilitated the escape of the tumor cells from CTL control [31].

Besides, it was shown that PD-L1 expression plays a critical role in differentiation of regulatory $\mathrm{T}$ cells (Tregs) and maintaining their suppressive function [32]. Because Tregs are important inhibitors of tumor-specific immune responses in the tumor microenvironment, PD-1/PD-L1mediated generation of Tregs can help as another layer of protection to immune evasion of tumors. Therefore, blockage of PD-1 or PD-L1 can activate the anti-tumor activity through both effector $\mathrm{T}$ cell activation and Treg inhibition. Additionally, PD-1/PD-L1 interactions can promote the differentiation of $\mathrm{CD}^{+}{ }^{+} \mathrm{T}$ cells into $\mathrm{FOXP}^{+}$Tregs [30], further suppressing the immune system and resulting in peripheral immune tolerance in cancer patients [33]. As well, the effects of PD-1 blockade can be mediated partially by B cells or NK cells. An in vitro study revealed that PD-1 could inhibit stimulating signals of $\mathrm{B}$ cell receptors, leading to restoration of $\mathrm{B}$ cell activation after transfecting gene fragments of PD-1 into B lymphoma cell lines [34]. It has been reported that $B$ cell antigen receptor signal inhibits B cell proliferation and function by inducing PD-1 expression [34] and Tumor-produced
IL-18 inhibits the function of NK cells via enhancing PD-1 expression [35].

In gene level, tumor cells can activate PD-L1 expression of via multiple oncogenic signaling pathways involv-

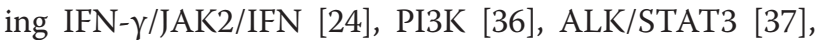
MEK/ERK/STAT1 [38], MYD88/TRAF6 [38] or exposure to inflammatory cytokines such as IFN- $\gamma$ [39] produced by infiltrating immune cells.

Altogether, PD-L1/PD-1 interation plays an important role in the reduction of specific $\mathrm{T}$ cell apoptosis, inhibition of immune response to tumors, and immune evasion of tumors [40]. The inhibition of PD-1/PD-L1 pathway may hamper the proliferation of activated effector T cell, causing the tumor evasion from the killing of CTLs, resulting in the weakening of anti-tumor immune response [41].

\section{PD-L1 blockade for cancer immunotherapy}

Given that PD-1 is highly expressed on lymphocytes infiltrating human tumors and circulating tumor-specific $\mathrm{T}$ cells [42], and together with that PD-L1 expression is correlated with prognosis in many cancers, which suggests that PD-L1 expression is a mechanism for tumor immune evasion [24,28,31], it is reasonable to consider the blockade of the PD-1/PD-L1 interaction may be a promising anticancer immunotherapy.

PD-L1 overexpression on mouse mastocytoma models inhibited tumor-directed $\mathrm{T}$ cell cytotoxicity in vitro and furthermore promoted apoptosis of tumor-specific $\mathrm{T}$ cells and immune evasion, these effects were neutralized by antibody-mediated blockade of PD-L1 [24,31]. Moreover in several experiments, blockade of PD-L1 could promote immune-mediated destruction of tumors which expressed PD-L1 $[24,43]$.

The clinical significance for prognosis of PD-L1 expression on tumors is controversial, correlating with inferior outcomes in some studies [44-47] and superior outcomes in others [39]. But the consensus is that there were no remarkable adverse immune-related events (irAE) reported in preclinical models of PD-1 or PD-L1 blockade. Overall, therapeutic blockade of PD-1 or PDL1 might break these multiple layers of immune inhibition, allowing effective anti-tumor $\mathrm{T}$ cell responses.

\section{Studies in NSCLC}

PD-1 overexpression on $\mathrm{CD}^{+} \mathrm{T}$ cells in NSCLC suggests a reduced production of various cytokines and $\mathrm{T}$ cell proliferation [48]. Abnormal expression PD-L1 has been identified in a range of $19 \%$ to $100 \%$ of NSCLC tumor cases [49-52], and associated with poor prognosis $[50,51]$. On the other hand, PD-L1 ${ }^{+}$cells are remarkably increased comparing with adjacent lung parenchyma, and PD-L1 expression on NSCLC cells also correlates with poor prognosis and shortened OS [48]. Hence it can be indicated that blockade of PD-1 interactions 
allows the tumor-specific $\mathrm{T}$ cell to unleash its full armamentarium of effector function on the NSCLC cells.

To date, a few antibodies which inhibit the PD-1 pathway by blockade of the PD-1 or PD-L1 have been invented.

\section{Nivolumab}

Nivolumab (BMS-936558) is a fully human IgG4 antibody blocking the PD-1 receptor [53]. Results of a phase I trial revealed an objective response rate (ORR) of $17 \%$ in 129 previously treated patients with advanced NSCLC [54]. Although the median PFS in the cohort was 2.3 months and the median OS was 9.9 months, these who responded enjoyed sustained benefits. Specifically, the 2-year OS rate was $24 \%$, and many remained in remission after completing 96 weeks of continuous therapy.

The most critical clinical data of nivolumab is from a phase Ib dose-escalation study enrolling 269 patients with various advanced solid tumors including NSCLC [55]. A promising response rate of $18 \%$ was observed in NSCLC patients. Rates of irAE (diarrhea, rash) appeared to be few and tolerable.

In other studies, nivolumab has also been tested in combination with platinum for first-line NSCLC, with an ORR of $33 \%$, and a grade 3 or $4 \mathrm{AE}$ rate of $49 \%$, and most of AEs were attributable to chemotherapy [56].

In the above trials, patients generally received anti-PD-1 antibody until progression for 1 to 2 years. If study participants achieved a durable response and then subsequently progressed after cessation of therapy, there was an opportunity for rechallenge at the time of progression [57].

\section{Lambrolizumab}

Lambrolizumab (MK-3475) is a humanized IgG4 antibody directed against PD-1 [58]. In a phase I open-label, doseescalation study enrolling advanced solid tumor patients, clinical activity of an unconfirmed partial response was observed in 1 patient with squamous NSCLC.

BMS-936559 (previously MDX-1105) is a fully human, PD-L1-specific IgG4 mAb [53]. A phase I study evaluating its anti-tumor activity reported an ORR of $10 \%$ in patients with NSCLC [59]. No cases of pneumonitis were reported.

\section{Correlation between PD-1/PD-L1 expression and EGFR/ KRAS expression}

In the clinical trials mentioned above, only a subset of patients responded to PD-1 blockade. And NSCLC is a disease characterized by driver mutation-defined molecular subsets, each with distinct clinicopathologic features and potentials for targeted therapies. Hence, it is appealing to explore the clinicopathological characteristics and molecular associations of NSCLC expressing PD-1 or PD-L1, which might be candidates for anti-PD1/PD-L1 immunotherapy.
As widely known, one of the most commonly mutated oncogenes in NSCLC patients is EGFR, a member of receptor tyrosine kinases superfamily. EGFR binds to extracellular ligands, dimerizes with them and auto-phosphorylate [60]. Then, EGFR acts as a key regulatory molecule in cellular signaling pathways, promoting tumor cell proliferation, invasion and metastasis [61]. EGFR is over-expressed by 40 to $80 \%$ of NSCLC, and the expression levels are correlated with the EGFR tyrosine kinase domain mutations [62].

EGFR tyrosine kinase inhibitors (TKIs) have been developed for the treatment of advanced NSCLC for years [63]. Unfortunately, only one part of NSCLC patients is sensible to EGFR-TKIs. Despite the initial response, tumors become TKI-resistant by acquiring either a secondary point mutation in EGFR (T790M) or additional alterations in other genes that bypass the requirement for ongoing signaling from the mutated EGFR [64].

Preliminary results have suggested that PD-L1 expression might be associated with a higher likelihood of response to PD-1 blockade [65], but reliable biomarkers associated with treatment response remain poorly known. Activation of EGFR pathway might be involved in suppressing the immune response in murine melanoma models either through activating regulatory $\mathrm{T}$ cells or reducing the levels of the $T$ cell chemoattractant [65]. Besides, other genes such as KRAS, BRAF and ALK are also important.

The results of the correlation between PD-1/PD-L1 expression and EGFR expression were controversial. Gettinger et al. concluded that EGFR or KRAS mutation status did not correlate with response rate of nivolumab for NSCLC patients [66]. Akbay et al.[67] found that activation of the EGFR pathway induced PD-L1 expression to help NSCLC tumors evade from the antitumor immune response. And it has been observed that EGFR signaling was independent of its effects on cell proliferation and survival. D'Incecco et al. [68] observed that PD-1 positive status was significantly associated with the presence of KRAS mutations $(P=0.006)$, while PD-L1 positive status was significantly associated with presence of EGFR mutations $(P=0.001)$. Patients with PD-L1 positive expression had higher sensitivity to EGFR-TKIs, longer time to progression and OS $(P=0.09)$ than PD-1 negative patients. Mu et al. observed that in stage I NSCLC patients the rate of PD-L1 over-expression was 39.9\% (65/163) but there was no significant correlation between PD-L1 expression and EGFR/KRAS/BRAF/ALK expression [51]. Similarly, Zhang et al. found that there was no significant relations between PD-L1 expression and EGFR/KRAS expression in lung adenocarcinoma [69].

Conclusively, the mentioned genes, not only EGFR, but also other several genes such as KRAS, BRAF or ALK, can not be satisfactory biomarkers for assessing the effects of blockage of PD-1/PD-L1 pathway based on the results of existing studies. 


\section{Future prospective}

Nowadays, the urgent need-to-be solved problems include the start time point of antibodies using, the duration of administration, the combination with other treatment modalities, the identifying of priority population and the overcoming of antibody resistance [28].

Referring to the combination with other treatment modalities, the distinct molecular and cellular mechanisms whereby CTLA-4 and PD-1 suggest that combined therapeutic strategy of these pathways might be synergistic for cancer immunotherapy. Preclinical models of combined CTLA-4 and PD-1 blockade have shown promising results without a significant increase in toxicity [70]. The clinical activity of checkpoint-blocking antibodies in the monotherapy setting is established, and the following step is to assess the safety and activity of combinations.

One noticeable point is that the therapeutic mechanism of PD-1/PD-L1 targeted therapy is different from chemotherapy and present molecular targeted therapies. Hence, novel assessment criteria for therapeutic effects are needed. We have proposed a preliminary evalation system for the effect of another widely used antitumor immunotherapy, cytokine-induced killer cell therapy [71], and the system for PD-1/PD-L1 targeted therapy is presumed to be similar to some extent.

Furthermore, the relative contributions of $\mathrm{T}$ cells, $\mathrm{B}$ cells, NK cells, NKT cells, DCs, and macrophages to the anti-cancer activity of PD-1 blockade should be clarified more deeply, as PD-1 is expressed on all of these types of immune cells.

Conclusively, PD-1 and PD-L1 are important checkpoints in tumor development. PD-1/PD-L1 pathway is a promising target for treating NSCLC, and its correlation with EGFR/KRAS mutation needs confirmation by progressive studies.

\section{Competing interests}

The authors declared that they have no competing interests.

\section{Authors' contributions}

CPW: proposed the main idea and drafted parts of the manuscript. MJ, YL, QL and XDL: searched for the literature and drafted the manuscript. WQZ, $H Z, X Z$ and JTJ: revised and edited the manuscript. All authors read and approved the final manuscript.

\section{Authors' information}

Mei Ji and Yan Liu share the first authorship.

\section{Acknowledgements \\ This work was funded by grants from the National Natural Science Foundation of China (81300422) to Yan Liu and the Jiangsu Health International Exchange Supporting Program to Xiao-Dong Li.}

\section{Author details}

'Department of Oncology, The Third Affiliated Hospital of Soochow University, Changzhou, China. 'Department of Hematology, The Third Affiliated Hospital of Soochow University, Changzhou, China. ${ }^{3}$ Department of Pathology, The Third Affiliated Hospital of Soochow University, Changzhou, China. ${ }^{4}$ Department of Epidemiology and Biostatistics, College of Public Health, University of South Florida, Tampa, USA. ${ }^{5}$ Department of Clinical
Oncology, Institute of Development, Aging and Cancer, Tohoku University, Sendai, Japan. ${ }^{6}$ Department of Biological Treatment, The Third Affiliated Hospital of Soochow University, Changzhou, China.

Received: 17 November 2014 Accepted: 26 December 2014

Published online: 16 January 2015

\section{References}

1. Siegel R, Naishadham D, Jemal A. Cancer statistics, 2013. CA Cancer J Clin. 2013;63:11-30

2. Lewis SZ, Diekemper R, Addrizzo-Harris DJ. Methodology for development of guidelines for lung cancer: Diagnosis and management of lung cancer, 3rd ed: American College of Chest Physicians evidence-based clinical practice guidelines. Chest. 2013;143:41S-50.

3. World Health Organization. Cancer fact sheet. http://www.who.int mediacentre/factsheets/fs297/en/. Accessed: 10 September 2012.

4. Stewart BW, Wild CP. World cancer report 2014. International Agency for Research on Cancer: Lyon; 2014.

5. Xu W, Yang G, Xu Y, Zhang Q, Fu Q, Yu J, et al. The possibility of traditional chinese medicine as maintenance therapy for advanced nonsmall cell lung cancer. Evid Based Complement Alternat Med. 2014;2014:278917.

6. Kobayashi K, Hagiwara K. Epidermal growth factor receptor (EGFR) mutation and personalized therapy in advanced nonsmall cell lung cancer (NSCLC). Target Oncol. 2013;8:27-33.

7. Dunn GP, Old LJ, Schreiber RD. The three Es of cancer immunoediting Annu Rev Immunol. 2004;22:329-60.

8. Dasanu CA, Sethi N, Ahmed N. Immune alterations and emerging immunotherapeutic approaches in lung cancer. Expert Opin Biol Ther. 2012;12:923-37.

9. Rosenberg SA, Spiess P, Lafreniere R. A new approach to the adoptive immunotherapy of cancer with tumor-infiltrating lymphocytes. Science. 1986;233:1318-21.

10. Matsushita H, Vesely MD, Koboldt DC, Rickert CG, Uppaluri R, Magrini VJ, et al. Cancer exome analysis reveals a T-cell-dependent mechanism of cancer immunoediting. Nature. 2012;482:400-4.

11. Intlekofer $A M$, Thompson CB. At the bench: preclinical rationale for CTLA-4 and PD-1 blockade as cancer immunotherapy. J Leukoc Biol. 2013;94:25-39.

12. Peggs KS, Quezada SA, Allison JP. Cancer immunotherapy: co-stimulatory agonists and co-inhibitory antagonists. Clin Exp Immunol. 2009;157:9-19.

13. Zikos TA, Donnenberg AD, Landreneau RJ, Luketich JD, Donnenberg VS. Lung T-cell subset composition at the time of surgical resection is a prognostic indicator in non-small cell lung cancer. Cancer Immunol Immunother. 2011;60:819-27.

14. Ishida Y, Agata Y, Shibahara K, Honjo T. Induced expression of PD-1, a novel member of the immunoglobulin gene superfamily, upon programmed cell death. EMBO J. 1992;11:3887-95.

15. Zhang X, Schwartz JC, Guo X, Bhatia S, Cao E, Lorenz M, et al. Structural and functional analysis of the costimulatory receptor programmed death-1. Immunity. 2004;20:337-47.

16. Riley JL. PD-1 signaling in primary T cells. Immunol Rev. 2009;229:114-25.

17. Keir ME, Butte MJ, Freeman GJ, Sharpe AH. PD-1 and its ligands in tolerance and immunity. Annu Rev Immunol. 2008;26:677-704.

18. Agata Y, Kawasaki A, Nishimura H, Ishida Y, Tsubata T, Yagita H, et al. Expression of the PD-1 antigen on the surface of stimulated mouse $T$ and $B$ lymphocytes. Int Immunol. 1996;8:765-72.

19. Tykodi SS. PD-1 as an emerging therapeutic target in renal cell carcinoma: current evidence. Onco Targets Ther. 2014;7:1349-59.

20. Dong H, Zhu G, Tamada K, Chen L. B7-H1, a third member of the B7 family, co-stimulates T-cell proliferation and interleukin-10 secretion. Nat Med. 1999;5:1365-9.

21. Latchman Y, Wood CR, Chernova T, Chaudhary D, Borde M, Chernova I, et al. PD-L2 is a second ligand for PD-1 and inhibits T cell activation. Nat Immunol. 2001;2:261-8.

22. Yamazaki T, Akiba H, Iwai H, Matsuda H, Aoki M, Tanno Y, et al. Expression of programmed death 1 ligands by murine T cells and APC. J Immunol. 2002;169:5538-45.

23. Freeman GJ, Long AJ, Iwai Y, Bourque $K$, Chernova T, Nishimura $H$, et al. Engagement of the PD-1 immunoinhibitory receptor by a novel B7 family member leads to negative regulation of lymphocyte activation. J Exp Med. 2000;192:1027-34 
24. Dong H, Strome SE, Salomao DR, Tamura H, Hirano F, Flies DB, et al. Tumor-associated B7-H1 promotes T-cell apoptosis: a potential mechanism of immune evasion. Nat Med. 2002;8:793-800.

25. Zou W, Chen L. Inhibitory B7-family molecules in the tumour microenvironment. Nat Rev Immunol. 2008;8:467-77.

26. Thompson $\mathrm{RH}$, Dong $\mathrm{H}$, Kwon ED. Implications of B7-1 expression in clear cell carcinoma of the kidney for prognostication and therapy. Clin Cancer Res. 2007;13:709s-15s.

27. Nomi T, Sho M, Akahori T, Hamada K, Kubo A, Kanehiro H, et al. Clinical significance and therapeutic potential of the programmed death-1 ligand/ programmed death-1 pathway in human pancreatic cancer. Clin Cancer Res. 2007;13:2151-7.

28. Wu C, Zhu Y, Jiang J, Zhao J, Zhang XG, Xu N. Immunohistochemical localization of programmed death-1 ligand-1 (PD-L1) in gastric carcinoma and its clinical significance. Acta Histochem. 2006;108:19-24.

29. Nurieva R, Thomas S, Nguyen T, Martin-Orozco N, Wang Y, Kaja MK, et al. T-cell tolerance or function is determined by combinatorial costimulatory signals. EMBO J. 2006;25:2623-33.

30. Barber DL, Wherry EJ, Masopust D, Zhu B, Allison JP, Sharpe AH, et al. Restoring function in exhausted CD8 T cells during chronic viral infection. Nature. 2006;439:682-7.

31. Iwai $Y$, Ishida M, Tanaka Y, Okazaki T, Honjo T, Minato N. Involvement of PD-L1 on tumor cells in the escape from host immune system and tumor immunotherapy by PD-L1 blockade. Proc Natl Acad Sci U S A. 2002;99:12293-7.

32. Francisco LM, Salinas VH, Brown KE, Vanguri VK, Freeman GJ, Kuchroo VK, et al. PD-L1 regulates the development, maintenance, and function of induced regulatory T cells. J Exp Med. 2009;206:3015-29.

33. Adeegbe DO, Nishikawa $\mathrm{H}$. Natural and induced T regulatory cells in cancer. Front Immunol. 2013;4:190.

34. Okazaki T, Maeda A, Nishimura H, Kurosaki T, Honjo T. PD-1 immunoreceptor inhibits B cell receptor-mediated signaling by recruiting src homology 2-domain-containing tyrosine phosphatase 2 to phosphotyrosine. Proc Natl Acad Sci U S A. 2001;98:13866-71.

35. Terme M, Ullrich E, Aymeric L, Meinhardt K, Desbois M, Delahaye N, et al. IL-18 induces PD-1-dependent immunosuppression in cancer. Cancer Res. 2011;71:5393-9.

36. Parsa AT, Waldron JS, Panner A, Crane CA, Parney IF, Barry JJ, et al. Loss of tumor suppressor PTEN function increases B7-H1 expression and immunoresistance in glioma. Nat Med. 2007;13:84-8.

37. Marzec M, Zhang Q, Goradia A, Raghunath PN, Liu X, Paessler M, et al. Oncogenic kinase NPM/ALK induces through STAT3 expression of immunosuppressive protein CD274 (PD-L1, B7-H1). Proc Natl Acad Sci U S A. 2008;105:20852-7.

38. Liu J, Hamrouni A, Wolowiec D, Coiteux V, Kuliczkowski K, Hetuin D, et al. Plasma cells from multiple myeloma patients express B7-H1 (PD-L1) and increase expression after stimulation with IFN-\{gamma\} and TLR ligands via a MyD88-, TRAF6-, and MEK-dependent pathway. Blood. 2007;110:296-304.

39. Taube JM, Anders RA, Young GD, Xu H, Sharma R, McMiller TL, et al. Colocalization of inflammatory response with B7-h1 expression in human melanocytic lesions supports an adaptive resistance mechanism of immune escape. Sci Transl Med. 2012;4:127ra137.

40. Kashani-Sabet M. Tumor progression by immune evasion in melanoma: role of the programmed cell death-1/programmed cell death-1 ligand 1 interaction. Cancer. 2010;116:1623-5.

41. Duraiswamy J, Kaluza KM, Freeman GJ, Coukos G. Dual blockade of PD-1 and CTLA-4 combined with tumor vaccine effectively restores T-cell rejection function in tumors. Cancer Res. 2013;73:3591-603.

42. Matsuzaki J, Gnjatic S, Mhawech-Fauceglia P, Beck A, Miller A, Tsuji T, et al. Tumor-infiltrating NY-ESO-1-specific CD8 + T cells are negatively regulated by LAG-3 and PD-1 in human ovarian cancer. Proc Natl Acad Sci U S A. 2010;107:7875-80

43. Hirano F, Kaneko K, Tamura H, Dong H, Wang S, Ichikawa M, et al. Blockade of B7-H1 and PD-1 by monoclonal antibodies potentiates cancer therapeutic immunity. Cancer Res. 2005;65:1089-96.

44. Thompson RH, Gillett MD, Cheville JC, Lohse CM, Dong H, Webster WS, et al. Costimulatory B7-H1 in renal cell carcinoma patients: Indicator of tumor aggressiveness and potential therapeutic target. Proc Natl Acad Sci U S A. 2004;101:17174-9.

45. Hamanishi J, Mandai M, Iwasaki M, Okazaki T, Tanaka Y, Yamaguchi K, et al. Programmed cell death 1 ligand 1 and tumor-infiltrating CD8+ $T$ lymphocytes are prognostic factors of human ovarian cancer. Proc Natl Acad Sci U S A. 2007;104:3360-5

46. Inman BA, Sebo TJ, Frigola X, Dong H, Bergstralh EJ, Frank I, et al. PD-L1 (B7-H1) expression by urothelial carcinoma of the bladder and BCG-induced granulomata: associations with localized stage progression. Cancer. 2007;109:1499-505.

47. Ohigashi Y, Sho M, Yamada Y, Tsurui Y, Hamada K, Ikeda N, et al. Clinical significance of programmed death-1 ligand-1 and programmed death-1 ligand-2 expression in human esophageal cancer. Clin Cancer Res. 2005;11:2947-53.

48. Zhang Y, Huang S, Gong D, Qin Y, Shen Q. Programmed death-1 upregulation is correlated with dysfunction of tumor-infiltrating CD8+ T lymphocytes in human non-small cell lung cancer. Cell Mol Immunol. 2010;7:389-95.

49. Hirahara K, Ghoreschi K, Yang XP, Takahashi H, Laurence A, Vahedi G, et al. Interleukin-27 priming of T cells controls IL-17 production in trans via induction of the ligand PD-L1. Immunity. 2012;36:1017-30.

50. Konishi J, Yamazaki K, Azuma M, Kinoshita I, Dosaka-Akita H, Nishimura M. B7-H1 expression on non-small cell lung cancer cells and its relationship with tumor-infiltrating lymphocytes and their PD-1 expression. Clin Cancer Res. 2004;10:5094-100.

51. Mu CY, Huang JA, Chen Y, Chen C, Zhang XG. High expression of PD-L1 in lung cancer may contribute to poor prognosis and tumor cells immune escape through suppressing tumor infiltrating dendritic cells maturation. Med Oncol. 2011;28:682-8.

52. Wolfle SJ, Strebovsky J, Bartz H, Sahr A, Arnold C, Kaiser C, et al. PD-L1 expression on tolerogenic APCS is controlled by STAT-3. Eur J Immunol. 2011;41:413-24.

53. Topalian SL, Hodi FS, Brahmer JR, Gettinger SN, Smith DC, McDermott DF, et al. Safety, activity, and immune correlates of anti-PD-1 antibody in cancer. N Engl J Med. 2012;366:2443-54.

54. Brahmer J. Nivolumab (anti-PD-1; BMS-936558; ONO-4538) in patients with non-small cell lung cancer (NSCLC): overall survival and longterm safety in a phase 1 trial. Presented at: IASLC 15th World Conference on Lung Cancer, October 2013. Sydney, Australia. M018.03.

55. Sosman J, Sznol M, McDermott D, Carvsjal R, Lawrence D, Topalian SL, et al. Clinical activity and safety of anti-programmed death-1 (PD-1) (BMS-936558/ MDX-1106/ONO-4538) in patients (PTS) with advanced melanoma (MEL) in ESMO. 2012. Vienna, Austria.

56. Rizvi N. A phase I study of nivolumab (anti-PD-1; BMS-936558, ONO-4538) plus platinum-based doublet chemotherapy (PT-doublet) in chemotherapy-naive non-small cell lung cancer (NSCLC) patients (pts). J Clin Oncol; 2013: 31(suppl; abstr 8072).

57. Lipson EJ, Sharfman WH, Drake CG, Wollner I, Taube JM, Anders RA, et al. Durable cancer regression off-treatment and effective reinduction therapy with an anti-PD-1 antibody. Clin Cancer Res. 2013;19:462-8.

58. Hamid O, Robert C, Daud A, Hodi FS, Hwu WJ, Kefford R, et al. Safety and tumor responses with lambrolizumab (anti-PD-1) in melanoma. N Engl J Med. 2013;369:134-44.

59. Chen DS, Irving BA, Hodi FS. Molecular pathways: next-generation immunotherapy-inhibiting programmed death-ligand 1 and programmed death-1. Clin Cancer Res. 2012;18:6580-7.

60. Nicholson RI, Gee JM, Harper ME. EGFR and cancer prognosis. Eur J Cancer. 2001;37 Suppl 4:59-15.

61. Scaltriti M, Baselga J. The epidermal growth factor receptor pathway: a model for targeted therapy. Clin Cancer Res. 2006;12:5268-72.

62. Suzuki M, Shigematsu H, Hiroshima K, lizasa T, Nakatani Y, Minna JD, et al. Epidermal growth factor receptor expression status in lung cancer correlates with its mutation. Hum Pathol. 2005;36:1127-34.

63. Kris MG, Natale RB, Herbst RS, Lynch Jr TJ, Prager D, Belani CP, et al. Efficacy of gefitinib, an inhibitor of the epidermal growth factor receptor tyrosine kinase, in symptomatic patients with non-small cell lung cancer: a randomized trial. JAMA. 2003;290:2149-58.

64. Ohashi K, Maruvka YE, Michor F, Pao W. Epidermal growth factor receptor tyrosine kinase inhibitor-resistant disease. J Clin Oncol. 2013;31:1070-80.

65. Pivarcsi A, Muller A, Hippe A, Rieker J, van Lierop A, Steinhoff M, et al. Tumor immune escape by the loss of homeostatic chemokine expression. Proc Natl Acad Sci U S A. 2007;104:19055-60.

66. Gettinger $\mathrm{SH}$. Efficacy of nivolumab in patients with previously traeted advanced non-small cell lung cancer: subpopulation response analysis in a phase I trial. Presented at: IASLC 15th World Conference on Lung Cancer, October 2013, Sydney, Australia. P2.11-038. 
67. Akbay EA, Koyama S, Carretero J, Altabef A, Tchaicha JH, Christensen CL, et al. Activation of the PD-1 pathway contributes to immune escape in EGFR-driven lung tumors. Cancer Discov. 2013;3:1355-63.

68. Gatalica Z, Snyder C, Maney T, Ghazalpour A, Holterman DA, Xiao N, et al.: Programmed Cell Death 1 (PD-1) and Its Ligand (PD-L1) in Common Cancers and Their Correlation with Molecular Cancer Type. Cancer Epidemiol Biomarkers Prev. 2014.

69. Zhang $Y$, Wang L, Li Y, Pan $Y$, Wang $R$, Hu H, et al. Protein expression of programmed death 1 ligand 1 and ligand 2 independently predict poor prognosis in surgically resected lung adenocarcinoma. Onco Targets Ther. 2014;7:567-73.

70. Curran MA, Montalvo W, Yagita H, Allison JP. PD-1 and CTLA-4 combination blockade expands infiltrating $T$ cells and reduces regulatory $T$ and myeloid cells within B16 melanoma tumors. Proc Natl Acad Sci U S A. 2010;107:4275-80

71. Li XD, Ji M, Zheng X, Ning ZH, Wu J, Lu B, et al. Evaluation of tumor response to cytokine-induced killer cells therapy in malignant solid tumors. J Transl Med. 2014;12:215.

\section{Submit your next manuscript to BioMed Central and take full advantage of:}

- Convenient online submission

- Thorough peer review

- No space constraints or color figure charges

- Immediate publication on acceptance

- Inclusion in PubMed, CAS, Scopus and Google Scholar

- Research which is freely available for redistribution 